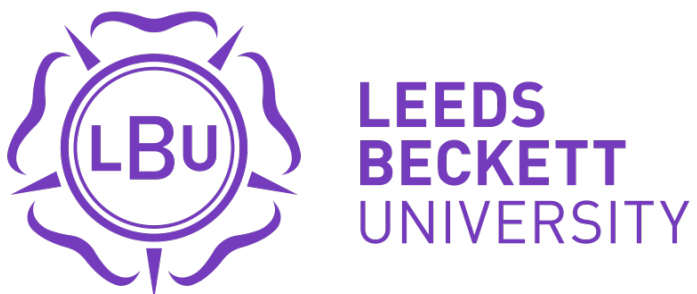

Citation:

Woodall, J and Freeman, C (2020) Where have we been and where are we going? The state of contemporary health promotion. Health Education Journal. ISSN 0017-8969 DOI: https://doi.org/10.1177/0017896919899970

Link to Leeds Beckett Repository record:

https://eprints.leedsbeckett.ac.uk/id/eprint/6425/

Document Version:

Article (Accepted Version)

The aim of the Leeds Beckett Repository is to provide open access to our research, as required by funder policies and permitted by publishers and copyright law.

The Leeds Beckett repository holds a wide range of publications, each of which has been checked for copyright and the relevant embargo period has been applied by the Research Services team.

We operate on a standard take-down policy. If you are the author or publisher of an output and you would like it removed from the repository, please contact us and we will investigate on a case-by-case basis.

Each thesis in the repository has been cleared where necessary by the author for third party copyright. If you would like a thesis to be removed from the repository or believe there is an issue with copyright, please contact us on openaccess@leedsbeckett.ac.uk and we will investigate on a case-by-case basis. 


\title{
Where have we been and where are we going? The state of contemporary health promotion
}

James Woodall and Charlotte Freeman

Health Promotion, School of Health and Community Studies, Leeds Beckett University, UK

\begin{abstract}
This paper seeks to critically discuss the current state of health promotion, arguing that ambiguity remains in its conceptual foundation, practice and education which is contributing to its decline in several parts of the world. Drawing on relevant literature, the paper re-examines the status of health promotion as a specialist discipline in its own right and suggests that the reaffirmation of this status can move health promotion from the margins to the mainstream of public health policy and practice. The paper briefly rehearses some common conceptualisations of health promotion before suggesting four tensions which, if resolved, could offer greater conceptual clarity and galvanise the contribution of the discipline in addressing individual and community health across the globe.
\end{abstract}

\section{Corresponding author:}

James Woodall, Health Promotion, School of Health and Community Studies, Leeds Beckett University, Calverley, 518 Portland Way, Leeds, LS1 3HE, UK

Email: J.Woodall@leedsbeckett.ac.uk 


\section{Introduction}

Publications that outlined the conceptual basis for health promotion were once relatively common. Not unexpectedly the proliferation of such publications peaked between the late 1980s and mid 1990s as health promotion, as an academic discipline and practice, became mainstreamed and supported by governmental organisations. Some of these papers offered conceptual models of health promotion, such as those provided by Beattie (1991), Tannahill (1985), Seedhouse (1997) and Caplan and Holland (1990). The contribution of this work was clear as it laid the foundation for discussion and dialogue, but also shaped health promotion at that time by contributing to a passionate and evolving debate (Nutbeam, 2018).

Much has changed in the field of health promotion and it is perhaps timely to re-engage in conceptual discussion about where health promotion is and where it may be going. Recent analysis, for example, suggests that health promotion has lost focus and is "going in all directions" (Lindström, 2018: 97). This paper seeks to identify and critically discuss the current state of health promotion, suggesting that it is a confused discipline with disharmony in relation to how it should be practised, taught or understood. This is not inconsequential, as it has weakened practice and academic training in some parts of the world (Warwick-Booth et al., 2018). In addition to outlining where health promotion currently 'is', four key tensions that require resolution will be examined in order to enable policy and practice to move forward.

At the beginning of the 1990s, it was anticipated that there would be rich theoretical discussion about the purpose of health promotion which would steer practice and policy into the twenty-first century (Bunton and Macdonald, 1992). On reflection, this was a utopian vision and one that was never fulfilled. Back then, the future of health promotion seemed strong with leadership and governmental backing in many countries - much of this backing, particularly in the United Kingdom, has since subsided. It is argued here that it is timely to engage in further analysis, given that there are concerns about the further decline of health promotion as a discipline and practice across several parts of the world (White and Wills, 2011).

Semantically, in the UK the term 'health promotion' has been substituted by alternatives such as 'health improvement' and 'health development' to capture the political flavour or preferences of the time (Tilford, 2018). In Canada, 'population health' was introduced as an alternative and in Australia, health promotion has been transformed into 'preventative health' (Van den Broucke, 2017). More broadly, some writers have positioned health promotion as being 'in crisis', especially in the UK and other parts of Western Europe, with neo-liberal policy climates creating a context unconducive to health promotion's philosophical basis (Woodall et al., 2018). Yet to some, including the authors, health promotion's potential contribution has never been stronger in tackling 'wicked' and complex challenges such as climate change (Catford, 2008) and in tackling Ebola and other high-threat diseases (Laverack, 2017).

Such dispute and lack of consensus, according to Duncan (2004), seems characteristic of the historical and present context of health promotion. While academic discussion about the 
conceptual basis of health promotion might divert attention from the practice of health promotion itself (i.e. improving individual and community health), there is concern that health promotion efforts - through lack of understanding or agreement - may actually cause harm (Le Fanu, 1994). Broad and fuzzy conceptualisations of health promotion have continued to lead to increased confusion, creating an uncertain framework for practice which may ultimately compound criticisms that the term 'health promotion' is a meaningless one (Johansson et al., 2009). It is argued here that health promotion is only causing damage to itself by not being clear about what it actually is, where tensions lie, and where it is heading. In contrast, this paper outlines a rationale for health promotion as a discipline in its own right and with its own recognised approaches and methods. It is suggested that health promotion is distinctive enough to stand alongside, and not in the shadow of, other disciplines, such as public health and environmental health.

We begin by rehearsing some common conceptualisations of health promotion as advanced in recognised models. We later identify four possible tensions within health promotion which, if resolved, would go some way to providing clarity to policy and practice. These tensions are by no means exclusive but derive from the broader literature, the authors' own experiences of research and teaching in health promotion, and wider conversations with practitioners and policy-makers both nationally in England and internationally. These tensions are: understanding the role of health promotion in the structure and agency debate; identifying the role for health promotion to work in both pathogenic and salutogenic ways; the utility of the Ottawa Charter in contemporary health promotion; and finally, the challenges posed to health promotion from a stalled settings approach.

The overall aim of the paper is to re-evaluate debate about what health promotion is and what it involves (Duncan, 2004) and to ensure the continued sustainability of health promotion as a discipline through providing a re-established conceptual foundation.

\section{Disciplinary status}

We refer throughout this paper to health promotion as a 'discipline' with its own ideology and ordered field of study (Davies, 2013). Disciplinary status matters for many reasons. It values the role that many professionals and academics have made to health promotion, offers credibility and, to some extent, enables the transfer of learning from one generation to the next (Krishnan, 2009). Some health promotion academics have dismissed this notion preferring to describe it as a 'field of action', with the argument proposed that health promotion fails to meet the standards to receive disciplinary status (Potvin and McQueen, 2007):

"Some scholars think that health promotion cannot be considered a scientific discipline because it lacks a distinctive institutional structure, an operational accreditation system, and an oversight by a professional body." (Van den Broucke, 2017: 765).

In contrast, the position advanced here, through six separate points, is that health promotion is a distinctive discipline. First, health promotion has its own and distinctive value base - these values are clear in espousing ways of working that are enabling and 
empowering and which support individuals and communities to gain control over their own health. Research shows, for instance, that equity, equality, social justice, empowerment, autonomy and participation are key values for practice which have differences with the values espoused in public health (Tilford et al., 2003). Second, health promotion has a specific knowledge and theoretical basis albeit drawn from a mix of established areas such as sociology, psychology and education (Bunton and Macdonald, 1992). Third, any discipline requires research to progress the development of theory and practice. Health promotion has a unique body of research, illustrated by its methods, values and approach which has advanced ways of thinking and refined practice (Woodall et al., 2018). Fourth, there exists a suite of dedicated journals specific to the field which enables academic debate and dialogue to be fostered. Fifth, health promotion has a community of scholars and defined professional competencies (Barry et al., 2009) and moreover has clear pathways for educational and professional progression through dedicated qualifications and training (Warwick-Booth et al., 2018). Finally, health promotion spans geographical and national boundaries reflected by the organisation of international, regional and national conferences and symposia (Davies, 2013).

Whether health promotion is, or is not, a discipline in its own right is a matter for debate, however we argue, as have others (Van den Broucke, 2017; Davies, 2013), that such status offers distinct benefits for the sustainability and longevity of practice and training in this area. Indeed, it also enables health promotion to shift from the margins of public health in some countries back to the mainstream. As Davis $(2013,10)$ has put it, "Health promotion needs to defend and uphold its position as a unique specialist discipline integral to public health".

\section{Common conceptualisations}

This paper does not intend to provide a thorough historical overview by tracing the steps of health promotion through the $20^{\text {th }}$ century via Marc Lalonde, Alma Ata or the Ottawa Charter. Those looking for such insight will find several papers that have done this very effectively (Duncan, 2004; Madsen, 2016; Madsen, 2018).

The notion that health promotion is contested, however, has been well-rehearsed throughout the past three decades (Green et al., 2019). This has resulted in huge variance in the way in which health promotion is ideologically viewed, conceptualised, practised and in who is responsible for its delivery (Duncan, 2004). As noted earlier, variations in semantics within the practice and discipline of health promotion cause confusion and place emphasis on different approaches and ideological underpinnings - a neo-liberal perspective, or a more socialist view, for instance (Lupton, 1995). This has influenced public health training and curriculum design in higher education leading to a plethora of courses purporting to provide the fundamental skills necessary for those seeking to work in health promotion (Warwick-Booth et al., 2018). While ambiguity in itself is frustrating, Duncan (2004) argues that this has characterised the discipline for some time, and continues to do so, but that this diversity should be embraced rather than retreated from to determine how health promotion is to be positioned. 
Currently, well-cited conceptual models of health promotion (Beattie, 1991; Tannahill, 1985; Seedhouse, 1997; Caplan and Holland, 1990) have had significant longevity given that most are now in their third decade of existence - this suggests either that these models sufficiently represent practice or that it is timely to re-consider their utility. They are largely premised on the agency versus structure dichotomy - or the view that health promotion is both about individuals taking responsibility for their own health and a structural viewpoint which view socioeconomic and environmental conditions as the driver influencing individual health. As a principle and as an activity, health promotion stands at the interface of structural forces and human agency (Kelly, 1989) as depicted in these popular conceptual models and the tensions arising from this stance will be discussed in the next section.

\section{Health promotion: the interface between structure and agency}

Ideological positions which embrace either collectivism or individualism have shaped, and at the same time confused, the way health promotion is conceptualised (Green et al., 2019). For example, a socialist perspective in health promotion advocates for collective solutions and interventions aimed at social justice to reduce inequalities in health (Davison and Davey Smith, 1995). On the other hand, debates from a politically conservative or neo-liberal perspective make a case for the primacy of the individual and prioritise the notion of personal choice. This approach has a strong laissez-faire slant and retreats from state intervention in social affairs via notions such as health choices (Cohen et al., 2000), emphasising the power of agency in health decision making.

Whilst Beattie (1991), Tannahill (1985), Seedhouse (1997) and Caplan and Holland's (1990) accounts of health promotion demonstrates a wide range of ideological views and indeed strategies for promoting health, health promotion has been historically criticised for being overly preoccupied by individual agency and the ways in which individuals behave (Kelly and Charlton, 1995; Nettleton and Bunton, 1995). This criticism has been particularly directed at those interventions addressing lifestyle choices and on individual level strategies to promote healthy living. Woodall (2016) suggests that such 'lifestyle drift' in health promotion - the inclination for policy that recognises the need to act on upstream social determinants, what may be broadly viewed as structural factors, only to drift downstream to focus on individual lifestyle factors (Popay et al., 2010) - remains difficult to resolve.

Acting on upstream social determinants influencing health avoids focusing on the individual and instead intervenes at a political or systems level (Stokols et al., 2003). A conservative position, however, may consider these macro-health promotion activities as an apparatus of an overly authoritarian and preaching 'nanny state.' Those adopting this view argue that the state should let its citizens choose how they wish to lead their own life (Lupton, 1995). In this individualist perspective, the enterprise of health promotion is challenged, with the only acceptable policy being based on the free availability of epidemiological risk information and liberty of choice over health decisions and practices (Davison and Davey Smith, 1995).

Those challenging this outlook suggest that the conservative perspective oversimplifies disease causation and fails to address the social determinants of health, such as poverty, unemployment and poor housing (Gregg and O'Hara, 2007). Traditional health education 
(i.e. health education associated with authoritarian values integral to a preventive medical model (Green, 2008)]), for instance, was condemned as being the embodiment of victim blaming (Green et al., 2019). Critiques from the left assert that individualising health fails to take into consideration the complex social factors and pressures that accompany behavioural choice and ignores the broader context in which personal behaviours are embedded (Nettleton and Bunton, 1995).

So where does this debate take us, recognising that that this tension is "neither esoteric or unimportant" (Duncan, 2004: 178)? It is important to note that there is nothing inherently 'good' or 'bad' in approaching health promotion from an individualist or collectivist position (Breslow, 1990); however, there seems, at times, to be a blinkered fixation with one or the other with problematic consequences (Minkler, 1999). There is, of course a 'third way', an ideological centre ground but such ideas have been challenged for reverting back to neoliberal principles (Wills et al., 2008). Indeed, recent examples have shown how health promotion driven policy in some contexts is focussed too heavily on behavioural determinants rather than tackling social, political and economic factors (Woodall, 2016). The drawbacks of current models, such as Beattie's or Caplan and Holland's view, is that they reinforce the extremes of agency and structure. Despite being based on an axis or continuum, mid-points are not considered and neither are progressions along the continua (Rawson, 1992). The 'extreme' positions of health promotion are often exacerbated in such models which, as we will see, can lead to polarised and highly-confusing viewpoints.

\section{Pathogenic or salutogenic health promotion and the values that bind}

The notion that conceptualisations of health influence how health promotion is viewed, is long-standing. Yet the health promotion community (i.e. academics, policy-makers, practitioners and students) has seen health promotion pulled in recent times to the extremes, seen as being both central to pathogenetic causes and salutogenic ones too. This leads to further ambiguity and challenge which has been rehearsed in several papers in relation to the distinction between health promotion and disease prevention (Tengland, 2010). The rationale underpinning health promotion's contribution to salutogenesis and pathogenesis has been poorly articulated and this ambiguity causes tension which requires some easing.

Recent literature has clearly demonstrated the utility of health promotion in disease outbreaks and emergencies (Laverack and Manoncourt, 2016; Laverack, 2017). Laverack and Manoncourt (2016) in relation to the Ebola outbreak suggested how health promotion strategies and values, particularly working with lay perspectives and engaging community members, was crucial to some of the attempts to mitigate the severity and spread of the outbreak. Whilst it is accepted that preventive measures are included within many conceptual frameworks of health promotion (Downie et al., 1996), authors note that more radical perspectives would see health promotion focussing primarily on advancing individuals towards the positive end of the disease-health continuum (Brubaker, 1983; King, 1994; Breslow, 1999).

Elsewhere, Nutbeam (1986: 115) carefully draws an important distinction between health promotion and disease prevention. He suggests: 
"Disease prevention is essentially an activity in the medical field dealing with individuals or particularly defined groups at risk. It aims to conserve health. It does not represent a positive vision of health that moves ahead, but is concerned with maintaining the status quo. Health promotion on the other hand, starts out with the whole population in the context of their everyday lives, not selected individuals or groups. Its goal is to enhance health."

There are highly eminent commentators who position health promotion towards pathogenesis and others who have positioned health promotion alongside salutogenesis (Eriksson and Lindström, 2008). The latter group regard salutogenesis as being closer to the fundamental principles of health promotion which align to positive concepts of health, dismissing the idea that health promotion can work in pathogenic ways. Pragmatically, it seems both naïve and ambitious to suggest that health promotion can contribute fully to both ends of health and disease spectrum. Such co-existence can only, it seems, occur if health promotion is regarded as a lens with which to view health and disease challenges from.

The health promotion 'lens' (Tilford, 2018) is formed from the underpinning values which make health promotion distinct. Values guide the way that practice and policy in health promotion are delivered. They give health promotion a distinctive 'voice'. However, they are rarely made transparent. While scholars have some disagreement as to the exact nature of the values of health promotion, it is arguable that their application enables health promotion to pursue both pathogenic and salutogenic causes. Without these values, it is likely that health promotion will lose its unique contribution which could lead to it being consumed by, or confused with, other disciplines, such as public health. This debate then leads to our assertion that health promotion makes a specialist contribution to the understanding of what 'health' means and the values underpinning the discipline enable its application in both in pathogenic and salutogenic ways.

\section{The primacy of the Ottawa Charter}

Preceding discussion has highlighted a series of challenges in the discipline of health promotion. Perhaps an obvious, albeit logistically challenging, way to resolve these tensions is a revised charter or strategy outlining and re-examining the purpose and aim of health promotion. To date, the Ottawa Charter has been a cornerstone of ideas and guided the way health promoters 'do' health promotion. However, the health promotion community do not seem to have reached consensus on whether the Ottawa Charter requires refinement or whether it should remain the pillar of policy and practice.

Despite consistent criticism that the Ottawa Charter is no longer relevant given current and contemporary challenges (Nutbeam, 2008), it remains the document which is consistently referred to by those within the discipline. Notwithstanding the various publications prior to the Ottawa Charter which made a case for health promotion (see Lalonde (1974)), the support of a WHO global conference brought health promotion to the attention of many (Tengland, 2010). Since Ottawa, there have been a plethora of further conferences seeking to replicate the notoriety of the event and to move the arguments and agenda forward. 
However, there is a consistent return to the Ottawa Charter given that it was the genesis of health promotion and the continued 'mouthpiece' for the field (Potvin and Jones, 2011). We would like to see a reconfigured document that addresses more clearly issues such as agency and structure and the pathogenic and salutogenic approaches previously discussed.

The arguments in favour of rejecting the Ottawa Charter for a new and improved reconfiguration are lucid and cogent. One of the prominent views was that it was, in effect, exclusionary in its approach with its focus on the western, industrialised nations (Nutbeam, 2008), excluding other communities around the world:

"the discourse informing the development of the Ottawa Charter masked underpinning power imbalances and Western-centric worldviews, while also silencing non-Western voices." (McPhail-Bell et al., 2013: 27)

The argument that since 1986 the world has significantly changed is also clear. This raises questions about the utility of the Charter in managing current issues such as globalisation, climate change and other important concerns (Nutbeam, 2008). In addition, evaluation of the effectiveness of the Ottawa Charter has not been forthcoming and some have pointed out the weakness of the Charter in reorienting health services - arguably the 'Achilles heel' of the document (Dixey et al., 2013).

It is of continual bemusement that almost annually a group of new academic papers appear which discuss the utility of the Ottawa Charter (McPhail-Bell et al., 2013; Nutbeam, 2008; Potvin and Jones, 2011) and yet the academic community is little further forward in agreeing to re-shape or continue to stand by the document. This debate highlights and acknowledges that no Charter can be static and that it would be useful for the health promotion community to form consensus on whether the Ottawa Charter remains the cornerstone document for practice and policy.

\section{Stalled settings approach}

The premise of the settings approach is that health is embedded in all social systems and environments (Dooris, 2007). This principle is now well established within health promotion, with the Ottawa Charter - as discussed previously - presenting a pivotal point in the development of a settings approach. The Ottawa Charter, as discussed previously, reflected growing consensus that health was not primarily the outcome of medical intervention, but an ecological concept which allowed for the interplay between social, political, economic and behavioural factors (Dooris et al., 1998). The settings approach embraces ecological perspectives as it challenges a reductionist focus on single issues towards an holistic vision of health and well-being determined by a interaction of environmental, organisational and personal factors within the places that people live their lives (Dooris, 2009). It offered a clear way to operationalise the Ottawa Charter in discrete geographical environments.

A settings approach was once seen as the most successful strategy to emerge from the Ottawa Charter (Hancock, 1999) and has been highly successful in a number of contexts, perhaps most notably in schools and in the healthy cities movement (Green et al., 2019). 
Some have highlighted the initial potential for the settings approach to move from the healthy cities idea to other environments:

"In the World Health Organization (WHO) we have for too long now overlooked the problem of health in prisons... The Healthy Cities Project has now been running for over ten years and there was no way, ten years ago, we could have predicted the potential of that project. Healthy Cities has become a movement, a global movement....And I would like to think at an occasion like this that it is possible to start a similar movement as we did for Health Cities but now for prisons." (Goos, 1996: 20)

However, in some settings there has been continual challenges to embedding the approach, such as competing organisational priorities and a lack of evidence of the success of the approach to secure full organisational commitment and resource. This has led to a considerable stalling of health promotion in particular contexts and sites. In respect to work in prisons, for example, the distance between the rhetoric of a settings-approach and translating this into practical guidance to aid delivery has been a major barrier. It has now been some time since the establishment of the concept of the health promoting prison and yet limited progress has taken place (Woodall, 2016). Moreover, health-promoting universities have been synonymous with the settings approach but the concept and practice too have been relatively slow to be adopted (Newton et al., 2016).

Perhaps a more significant concern has been the inability of the settings approach to engage in the digital age and fully embrace the notion of 'virtual settings for health'. The exponential growth of the Internet, and social media particularly, has created opportunities for health promotion to locate in 'virtual' settings, for example through the significant benefits to be gained from social networking (Moorhead et al., 2013), and yet the uptake and execution of this has not been forthcoming.

Virtual settings for health have the potential to reinforce an individualistic view of health promotion that seems to dilute the focus on social determinants (Lupton, 2015) emphasising the neo-liberal agenda in health promotion mentioned earlier. The notion that health is something that is controlled by the individual, that self-responsibility is key to a 'healthy life', and that individuals have free agency in their health actions, is potentially reinforced by social media. In addition, others have argued that virtual settings have been extremely limited in their ability to influence political and environmental structures with only a few tangible examples of how the virtual environment itself has been made 'healthier' (Loss et al., 2014). The online environment is often the antithesis of 'healthy' and, in extreme cases, social networking sites may glorify self-harm or suicide and cause mental and emotional distress (Oberst et al., 2017).

The theory of settings-based health promotion suggests that the approach will be best realised with synergistic effects across settings, but there are few examples where this has happened successfully. Commentary on the role of the virtual world for health promotion efforts suggests that there is still some way to go and that refinement towards a more sophisticated approach is necessary. There is huge potential for virtual settings to connect 
more effectively with physical environments and settings, but so far this potential has not been fully realised (Loss et al., 2014).

\section{Conclusions}

Authors have looked to history to resolve disputes and challenges in health promotion and yet have not moved the debate further forward (Duncan, 2004). Few commentators have offered a concrete solution to the current challenges posed. This paper has outlined the state of health promotion, as a concept, as it stands today. It is a confused discipline with generally limited consensus on how it should be practiced, taught or understood. This is far from trivial, as it has created a conceptual weakening of the discipline which has led, in part, to its eradication in some parts of the world, such as the UK. It is heartening, however, to still observe health promotion flourishing - often where more egalitarian structures exist and where there are clear political levers to influence change. Some countries in subSaharan African are often synonymous with this egalitarian structure where there are clear statutory services dedicated to health promotion policy and practice, albeit with resource challenges (Dixey, 2013).

It is worth noting that health promotion is not the only discipline which displays tensions and disputes (Jawitz, 2009). However, this paper has identified four tensions within health promotion which, if resolved, could propel the discipline forward. It has been argued that entrenched debates between agency versus structure have offered limited progression. It may now be time to consider the midpoints between these two positions. Likewise, health promotion should not to be committed to either salutogenesis or pathogenesis. Rather, its values can be the lens through which to understand both health and disease. To consolidate the discipline, longstanding debates surrounding the utility of the Ottawa Charter must be resolved and the potential of its legacy, the settings approach, be re-evaluated and brought up to date.

These four tensions have, though not singlehandedly, seemed to hold the discipline back. The aim of this paper has been to work toward resolving some of the difficulties that are currently putting the discipline in jeopardy in some parts of the world. In addition, it is a call to inject optimism about the discipline and re-galvanise efforts to establish health promotion as an important element of improving the health of individual and communities. As noted by others:

"Even if no ready answers can be found, the asking will help better define the subject matter and create the discipline to discover the true potential of health promotion" (Rawson, 1992: 221)

Ultimately, this paper seeks to provoke debate and while solutions to resolve the challenges outlined are demanding the task is not insurmountable. We propose the health promotion community - including practitioners, policy-makers and academics - come together via representative bodies (e.g. IUHPE) to collectively find answers to the challenges posed. That said, we would suggest that a useful starting point is far greater conceptual clarity around health promotion, allowing flexibility but also some clear tenets that health promotion 
stakeholders can subscribe to. This could, we feel, include the reconfiguration of the principles embedded in the Ottawa Charter. 


\section{References}

Barry MM, Allegrante JP, Lamarre M-C, et al. (2009) The Galway Consensus Conference: international collaboration on the development of core competencies for health promotion and health education. Global Health Promotion 16: 05-11.

Beattie A. (1991) Knowledge and control in health promotion: a test case for social policy and social theory. In: Gabe J, Calnan M and Bury M (eds) The Sociology of the health service. London: Routledge, 162-202.

Breslow L. (1999) From disease prevention to health promotion. Journal of the American Medical Association 281: 1030-1033.

Brubaker BH. (1983) Health promotion a linguistic analysis. Advances in Nursing Science 5: 1-14.

Bunton R and Macdonald G. (1992) Health promotion. Disciplines and diversity, London: Routledge.

Caplan R and Holland R. (1990) Rethinking health education theory. Health Education Journal 49: 1012.

Catford J. (2008) Food security, climate change and heath promotion: opening up the streams not just helping out down stream. Health Promotion International 23: 105-108.

Cohen JE, Milio N, Rozier RG, et al. (2000) Political ideology and tobacco control. Tobacco Control 9: 263-267.

Davies JK. (2013) Health promotion: a unique discipline? Auckland: Health promotion forum of New Zealand.

Davison C and Davey Smith G. (1995) The baby and the bath water: examining socio-cultural and free-market critiques of health promotion. In: Bunton R, Nettleton $\mathrm{S}$ and Burrows $\mathrm{R}$ (eds) The sociology of health promotion. London: Routledge, 91-99.

Dixey R. (2013) After Nairobi: can the international community help to develop health promotion in Africa? Health Promotion International 29: 185-194.

Dixey R, Cross R, Foster S, et al. (2013) Foundations of health promotion. In: Dixey R (ed) Health promotion: global principles and practice. London: CABI.

Dooris M. (2007) Healthy settings: past, present and future. Unpublished PhD thesis. School of Health \& Social Development. Victoria: Deakin University.

Dooris M. (2009) Holistic and sustainable health improvement: the contribution of the settingsbased approach to health promotion. Perspectives in Public Health 129: 29-36.

Dooris M, Dowding G, Thompson J, et al. (1998) The settings-based approach to health promotion. In: Tsouros A, Dowding G, Thompson J, et al. (eds) Health promoting universities: concept, experience and framework for action. Copenhagen: WHO, 21-32.

Downie RS, Tannahill C and Tannahill A. (1996) Health promotion. Models and values, Oxford: Oxford University Press. 
Duncan P. (2004) Dispute, dissent and the place of health promotion in a "disrupted tradition" of health improvement. Public understanding of science 13: 177-190.

Eriksson M and Lindström B. (2008) A salutogenic interpretation of the Ottawa Charter. Health Promotion International 23: 190-199.

Goos C. (1996) Perspectives on healthy prisons. In: Squires N and Strobl J (eds) Healthy prisons a vision for the future. Liverpool: The University of Liverpool, Department of Public Health.

Green J. (2008) Health education - the case for rehabilitation. Critical Public Health 18: 447-456.

Green J, Cross R, Woodall J, et al. (2019) Health promotion. Planning and strategies, London: Sage.

Gregg J and O'Hara L. (2007) Values and principles evident in current health promotion practice. Health Promotion Journal of Australia 18: 7-11.

Hancock T. (1999) Creating health and health promoting hospitals: a worthy challenge for the twenty-first century. International Journal of Health Care Quality Assurance 12: 8-19.

Jawitz J. (2009) Academic identities and communities of practice in a professional discipline. Teaching in Higher Education 14: 241-251.

Johansson H, Weinehall L and Emmelin M. (2009) "It depends on what you mean": a qualitative study of Swedish health professionals' views on health and health promotion. BMC health services research 9: 191.

Kelly MP. (1989) Some problems in health promotion research. Health Promotion 4: 317-330.

Kelly MP and Charlton B. (1995) The modern and postmodern in health promotion. In: Bunton R, Nettleton S and Burrows R (eds) The sociology of health promotion. London: Routledge, 7890.

King PM. (1994) Health promotion: the emerging frontier of nursing. Journal of Advanced Nursing 20: 209-218.

Krishnan A. (2009) What are Academic Disciplines? Some observations on the Disciplinarity vs. Interdisciplinarity debate. ESRC National Centre for Research Methods NCRM Working Paper Series 03/09.

Lalonde M. (1974) A new perspective on the health of Canadians: a working document. Ottawa: Health and Welfare Canada.

Laverack G. (2017) Health promotion in disease outbreaks and health emergencies, London: CRC Press

Laverack $G$ and Manoncourt E. (2016) Key experiences of community engagement and social mobilization in the Ebola response. Global Health Promotion 23: 79-82.

Le Fanu J. (1994) Preventionitis: the exaggerated claims of health promotion, London: Social Affairs Unit.

Lindström B. (2018) Workshop salutogenesis and the future of health promotion and public health. Scandinavian journal of public health 46: 94-98. 
Loss J, Lindacher V and Curbach J. (2014) Online social networking sites-a novel setting for health promotion? Health \& Place 26: 161-170.

Lupton D. (1995) The imperative of health. Public health and the regulated body, London: Sage.

Lupton D. (2015) Health promotion in the digital era: a critical commentary. Health Promotion International 30: 174-183.

Madsen W. (2016) Early 20th century conceptualization of health promotion. Health Promotion International 32: 1041-1047.

Madsen W. (2018) History in health: health promotion's underexplored tool for change. Public Health 154: 118-122.

McPhail-Bell K, Fredericks B and Brough M. (2013) Beyond the accolades: a postcolonial critique of the foundations of the Ottawa Charter. Global Health Promotion 20: 22-29.

Minkler M. (1999) Personal responsibility for health? A review of the arguments and the evidence at century's end. Health Education \& Behavior 26: 121-140.

Moorhead SA, Hazlett DE, Harrison L, et al. (2013) A new dimension of health care: systematic review of the uses, benefits, and limitations of social media for health communication. Journal of medical Internet research 15: e85.

Nettleton S and Bunton R. (1995) Sociological critiques of health promotion. In: Bunton R, Nettleton $\mathrm{S}$ and Burrows R (eds) The sociology of health promotion. London: Routledge, 41-58.

Newton J, Dooris M and Wills J. (2016) Healthy universities: an example of a whole-system healthpromoting setting. Global Health Promotion 23: 57-65.

Nutbeam D. (1986) Health promotion glossary. Health Promotion 1: 113-126.

Nutbeam D. (2008) What would the Ottawa Charter look like if it were written today? Critical Public Health 18: 435-441.

Nutbeam D. (2018) Health education and health promotion revisited. Health Education Journal: 0017896918770215.

Oberst U, Wegmann E, Stodt B, et al. (2017) Negative consequences from heavy social networking in adolescents: The mediating role of fear of missing out. Journal of adolescence 55: 51-60.

Popay J, Whitehead M and Hunter DJ. (2010) Injustice is killing people on a large scale-but what is to be done about it? Journal of Public Health 32: 148-149.

Potvin L and Jones CM. (2011) Twenty-five years after the Ottawa Charter: the critical role of health promotion for public health. Canadian Journal of Public Health 102: 244-248.

Potvin L and McQueen DV. (2007) Modernity, public health, and health promotion. In: McQueen DV, Kickbusch I, Potvin L, et al. (eds) Health and modernity. The role of theory in health promotion. New York: Springer, 12-20.

Rawson D. (1992) The growth of health promotion theory and its rational reconstruction. In: R. B and G M (eds) Health promotion: disciplines and diversity. 202-224. 
Seedhouse D. (1997) Health promotion: philosophy, prejudice and practice, New York: John Wiley \& Sons.

Stokols D, Grzywacz JG, McMahan S, et al. (2003) Increasing the health promotive capacity of human environments. American Journal of Health Promotion 18: 4-13.

Tannahill A. (1985) What is health promotion? Health Education Journal 44: 167-168.

Tengland P-A. (2010) Health promotion or disease prevention: a real difference for public health practice? Health care analysis 18: 203-221.

Tilford S. (2018) Using a health promotion lens. International Journal of Health Promotion and Education 56: 68-69.

Tilford S, Green J and Tones K. (2003) Values, health promotion and public health. Leeds: Centre for Health Promotion Research, Leeds Metropolitan University.

Van den Broucke S. (2017) Strengthening public health capacity through a health promotion lens. Health Promotion International 32: 763-767.

Warwick-Booth L, Cross R, Woodall J, et al. (2018) Health promotion education in changing and challenging times: reflections from England. Health Education Journal 0:

0017896918784072.

White J and Wills J. (2011) What's the future for health promotion in England? The views of practitioners. Perspectives in Public Health 131: 44-47.

Wills J, Evans D and Samuel AS. (2008) Politics and prospects for health promotion in England: mainstreamed or marginalised? Critical Public Health 18: 521-531.

Woodall J. (2016) A critical examination of the health promoting prison two decades on. Critical Public Health 26: 615-621.

Woodall J, Warwick-Booth L, South J, et al. (2018) What makes health promotion distinct? Scandinavian journal of public health 46: 118-122. 